\author{
Ameer H. Morad \\ Al-Khwarizmi College of \\ Engineering, University of \\ Baghdad, Baghdad, Iraq \\ ameer@kecbu.uobaghdad.edu.iq
}

Received on: $15 / 11 / 2018$

Accepted on: 10/01/2019

Published online: 25/12/2019

\section{The Reality of University Education in Iraq: Problems and Solutions Through Adoption of Credit Hours System}

\begin{abstract}
Accreditation has been adopted in the system of credit hours in all international universities and most of the Arab universities because it is characterized by the consolidation of the principle of education and learning by adapting to the ability of the learner to accept the information while maintaining the level of scientific probity. However, few countries, including Iraq, have not adopted this type of education system. This paper presents a brief overview of the system of credit hours and the diagnosis of some of the problems facing education in Iraq at the present time, which rely on the old education systems represented by the annual and quarterly education system, and to develop solutions to those problems by relying on the teaching hour's system.
\end{abstract}

Keywords- Credit Hour System, High Education,

How to cite this article: A.H. Morad, "The Reality of University Education in Iraq: Problems and Solutions Through Adoption of Credit Hours System," Engineering and Technology Journal, Vol. 37, Part C, No. 4, pp. 487$491,2019$.

\section{Introduction}

That evolution and discoveries are features accompany the historical stages that are human, and the most prominent areas is education. In the early ages, education was carried out by a group of scholars and talents, and each scholar had a group of imitators. In the later stages, the idea of scientific institutions (schools, universities and research centers) crystallized. Several educational systems were introduced, the most recent being the Credit Hours System according to the Bologna Process. Education ministers from 29 European countries met in the Italian city of Bologna and through a series of meetings, which culminated in a standard education system. In this system, the unit is calculated from a set of hours (equivalent to 25 hours according to ECTS: European Credit Transfer System), which includes the total number of hours of teaching (Contact Hours) and the number of hours of study and preparation (Work Load), which gives the total The time spent by the student in order to end all educational activities such as: theoretical lectures, practical lectures, study, self-learning, projects, jobs, oral interviews, and examinations. To view this system you can enter the link [1-9]. The system of credit hours is one of the best systems of higher education adopted by universities in the world has proved successful in this application, giving the student the freedom and flexibility in the selection of courses for each semester, depending on the circumstances in that semester or year.

The academic year in the credit hours system consists of three semesters, first, second, and summer semester (optional non-binding for students). Each of the first and second semesters consists of 15 weeks and the summer semester consists of eight weeks, thus doubling the number of hours studied per week. The summer semester is very important and beneficial for students, as they can avoid any failure or failure arising during their university studies, which helps them to graduate with their peers without delay. Accredited Time: This is the basic unit for measuring what students receive when they study in the course system. This is one theoretical hour or two hours per week given during a full semester. The hours adopted in a course can only be theoretical or practical, or a combination of theoretical and practical. In fact, the purpose of this research is not to define the system of credit hours, but to identify some of the problems found in the educational system adopted in Iraq and to identify the solutions available in the system of education hours adopted and applied in some countries of the Middle East, especially Jordan [1, $4,10-12]$.

\section{Problems of the Education System in Iraq}

As a result of my dependence on the modern education systems, including the systems of 
teaching at the accredited hours and through the practice of teaching for more than two years in some universities in neighboring countries, which rely on such systems, and experience in education and practice teaching in Iraqi universities for more than twenty years, The problems in the reality of education in Iraq in the current situation can be solved through the system of credit hours. In fact, the research approach is based on the following:

- Diagnosis of some problems in the reality of higher education in Iraq, which directly affect the level of scientific sensitivity in education.

- Through my experience in both systems I tried to find solutions to these problems based on some paragraphs and principles of education in the system of credit hours.

- The research does not aim to acquaint the reader with the details of the system of credit hours, and the reader can resort to the sources of the research in order to familiarize deeply with the basic principles of the system.

In the following paragraphs, a set of problems is diagnosed and solutions are suggested.

I. Delaying the start of the study in the first semester for students of the first stage

It is known that teaching in the Iraqi universities in the first semester of the first stage begins in mid-November due to the delayed announcement of the final results of the preparatory students by the Ministry of Education and the central admission procedures in the Ministry of Higher Education and Scientific Research. This means that the remainder of the semester is only 4 to 6 weeks note that the semester is 15 weeks.

In order to solve this problem, the system of accredited hours is adopted. The student has the right to register at the beginning of September (i.e. at the beginning of the first semester) or the beginning of February of the following year (i.e. at the beginning of the second semester). Successful students can be accepted in the first round of the preparatory course, whose results are announced in August at the latest, to start studying at universities from the beginning of the first semester without delay. Successful students in the second round of preparatory school are admitted to universities at the beginning of the second semester. The semester is fifteen weeks.

\section{Enrolment or dismissal of students}

According to the educational system adopted at the Iraqi universities, the registration of the student is cancelled and the student is dismissed from the study due to his/her failure in one academic subject twice for (50 to 56) scientific subjects taught by the student during four academic years. This is an imbalance in modern educational systems based on the principle of inequality in the ability of students and the right of students to education and learning and to choose their course of education, which is commensurate with their ability to accept information to achieve the highest level of education within their scientific competence.

In the credit system, the emphasis is on a specific measure of the student's level of learning (or levels). This is the Cumulative Grade Point Average (GPA) of the subjects studied by the student.

The cumulative average is the average grade of the subjects studied by the student to be successful or withdrawn until the last semester of his/her studies. The grade is calculated by multiplying the number of subjects in each unit by the end of the last semester divided by the total number of credit hours end of the current semester as shown in Eq. (1).

$$
\text { CGPA }=\frac{\sum_{i}(\text { Subject Score } * \text { Subject Units })_{i}}{\sum_{i} \text { Units }} \cdots
$$

Indicator (i) represents the number of items studied by the student up to the end of the current semester.

In order for the student to continue studying, this measure should not be less than (2 points) or (C) in the GPA system. A student with a cumulative average of less than 2 points is warned in any semester except for the summer semester and the first semester for first year students. When the student receives a warning, he/she must cancel his/her activity by raising his/her cumulative average above ( 2 points), within a maximum period of two semesters from the warning date. The student is dismissed if he/she fails to cancel the warning after two semesters.

The student has the right to re-study any subject in his/her study plan in which he/she succeeds in low grades below (2 points) to raise his cumulative average to the acceptable limit (2 points) or regardless of his/her cumulative average and treat his/her mark after the return to a maximum of (B) And recalculated its cumulative average.

A student is separated from a specialization that earns less than (one point) in the cumulative average in any semester after the first semester.

As well as the GPA in determining the level of scientific acceptance of the student and continuing the study, in addition to other things that support scientific hardness, such as the absence of a second role and the mechanism of withdrawal from a subject. The student must reexamine each article in which he obtained a result 
of a deposit (F), and the return is compulsory for the compulsory subjects in the plan.

The withdrawal mechanism allows the student to withdraw from one or more courses within a maximum period of 12 weeks and 6 weeks from the beginning of the summer semester. The duration of the first and second semester (15 weeks) and the lectures ( 8 weeks) a note (withdrawn) shall be recorded in his record. The result of the withdrawal shall not be less than the minimum number of credit hours registered for the student from the minimum allowed (12) credit hours in the first and second semester.

This mechanism supports scientific probity by the fact that the student registered on a particular subject and continuing the study and could not keep up with the scientific requirements of the course material and failed to obtain a good degree of pursuit (which is the degree of mid-term exam and degrees of activities from short tests and duties), the student allowed to requested withdrawal to be registered by the same article in the other semester. As a result, students are liquidated in order to keep the diligent students and those who have gathered good will, thus allowing the teacher to design the final exam questions at a high level commensurate with the required sobriety.

III. Students' workload and the varying susceptibility of student absorption

In the system of education approved in Iraq (annual and quarterly), the number of subjects is determined by seven or eight subjects for all students, despite the difference in students' absorption. Therefore, there is a reluctance for a large number of students, especially in scientific studies, which affects the scientific level of students in terms of the amount of information acquired. For students of engineering colleges where the level of high return or successful students do not exceed the rates of 60 of 100 and as a result graduate student was not able to the scientific requirements for specialization.

The education system is distinguished by the principle of individual differences in the ability to learn, so the minimum number of credit hours taught by a registered student to obtain a bachelor's degree (12) hours (or four subjects) for the first and second grades and (6) hours (or two subjects) for the summer semester.

The maximum number of credit hours taught by a registered student for a bachelor's degree (18) is a credit hour (or six subjects) for the first and second semesters and (9) hours (or three subjects) approved for the summer semester. A student with a cumulative GPA of CGPA ( 3 out of 4 or more) and a student who is expected to graduate in this semester are allowed to register (21) credit hours (or seven course items).

The student's bachelor's degree should not exceed 6 years for four-year specializations and 7 years for five-year specializations.

This allows the student to determine the learning load that is proportional to his ability to achieve the best level of learning.

\section{$I V$. The principle of punishment and reward}

The laws of the educational system adopted in Iraq are very much focused on punishing the student who is failing in his or her academic performance, for example, the student would be dismissed from the study in the event of failing twice in any subject in the curriculum, and there is no mechanism to support and encourage the diligent student. A diligent student will remain the length of the specified study program $(4,5$ or 6 years) with his/her fellow students of the intermediate and accepted in their scientific performance.

While in the education system of the adopted hours as well as the punitive measures, referred to in the above, there is a mechanism to differentiate students in terms of their scientific performance, as diligent students can shorten the duration of the study and preceded their colleagues. The student is entitled to enroll in the academic year as in Eq. (2):

$$
\begin{aligned}
(18)_{1 \text { st Semester }} & +(18)_{2 \text { nd Semester }} \\
& +(18)_{3 \text { rd Semester }} \\
& =45 \text { Cedit Hours } \ldots
\end{aligned}
$$

And the minimum expected duration for the student to graduate for four years (assuming that the number of credit hours for graduation 135) $=135 / 45=3$ years.

The minimum expected duration of the student's graduation is five years (assuming that the number of credit hours for graduation is 165 ) $=$ $165 / 45=3.66$ years.

In addition, a student who has a cumulative average above (B) is entitled to enrol 21 credit hours instead of (18), thus reducing the duration of the study further.

\section{$V$. Disparity in the degree of graduation rate of students in the corresponding colleges}

The problem is one of the things that is detrimental to graduate students. The degree of graduation rate does not give a real impression of the level of academic attainment. There are colleges with high reputation and high grades, however, graduation rates is low due to college policy. While there are less confrontational colleges and the scientific level of their graduates 
is below the level but their grades are high. This, of course, affects the graduates of the hardworking colleges in the process of competing for postgraduate studies and in the opportunity to obtain employment .

In the credit hours system, as this problem is prevented by the use of the Grade Point Average (GPA) system, the grades are converted from the $100 \%$ number system to characters not linked to fixed periods of grades, but vary depending on the nature of the degree limits of the subject. This inevitably means that all letters are present (A, B $+, \mathrm{B}, \mathrm{C}+\ldots)$. This means that after calculating the final grade of students in a given subject, the grades are arranged in descending order and divided into periods. These periods are indicated by letters and for each letter of equivalence weight as shown in Table (1). The percentage of the appearance of each character follows the college or teaching policy so as to achieve normal distribution of the marks.

Table 1: Test results of deep beam specimens

\begin{tabular}{lllllllll}
\hline \hline Symbol & $\mathrm{A}$ & $\mathrm{B}+$ & $\mathrm{B}$ & $\mathrm{C}+$ & $\mathrm{C}$ & $\mathrm{D}+$ & $\mathrm{D}$ & $\mathrm{F}$ \\
\hline Grade & 4 & 3.5 & 3 & 2.5 & 2 & 1.5 & 1 & 0.5 \\
\hline
\end{tabular}

\section{Conclusion}

By presenting some of the problems in the educational process in Iraq and how to solve them by relying on the system of credit hours, it is necessary to work hard to change the education system and keep up with the development in this field and not to put weak and audible obstacles from here and there with the difficulty of applying the system of credit hours. For example the shortage of faculty members and the infrastructure of the halls and laboratories as well as the lack of experience of the teaching staff and the student in such an educational system. In my view, the real reason I felt through the fact that most of the lecturers want the current system because it does not need a lot of commitments as the educational process shortened to lecture with a few quizzes during the year and the final exam so they have no desire to change.

I agree with everyone that change is not easy, and that the transition process needs an extraordinary effort, but not impossible, and it is possible to benefit from the experiences of universities in the countries surrounding us, which are successful and clear experiences, which encouraged officials in those countries in the later stages to adopt the system of education hours in the study Secondary education.

\section{Suggestions and Recommendations}

At the end of the research, a set of recommendations was included for officials and those interested in developing the reality of education, including:

I. Officials in higher education must take the utmost steps to save the reality of education in Iraq and develop realistic solutions to raise the level and outcomes of education.

II. Conducting a series of seminars and educational workshops in the universities through which to define the system of credit hours and present the experiences of neighboring countries in the implementation of the system .

III. In the beginning, the credit hours system can be implemented on an experimental basis at a number of universities, for example three universities, providing the requirements for the success of the experiment and assessing the results of the application. In the case of success, the experiment can then be circulated to the rest of the universities.

IV. Provide the summer course requirements from the halls and teaching staff and provide a financial budget to compensate the teachers, possibly, through the payment of encouraging additional hours or lump-sum rewards.

\section{References}

[1] Salah Alyan and Sameh Bakir, credit hours, modern Academy of Computers Science Management technology in Maadi, 2013.

[2] Alsaeed Alshamy, Credit Hour System and Student Workload at Alexandria University: a possible paradigm shift, Tuning Journal for Higher Education, Volume 4, Issue No. 2, May 2017, 277-309, 2017.

[3] Valdosta State University, Credit and Contact Hour and Instructional Equivalencies Guidelines, Posted online at www.valdosta.edu/academics/academicaffairs/docume nts/credit_contact_guidelines.pdf, June 27. 2017.

[4] Mohamed Hanafy Morsy, and others, Credit Hours Policy \& Hybrid Problem-Based Learning (PBL) Curriculum Reform: An Experience of Najran School of Medicine KSA, AASCIT Journal of Education, Vol.1(2), P.P 21-25, 2015

[5] University of Wisconsin, Madison Credit Hour Policy, UAPC Doc V5. 5 1, Page 1 of 6, 2017.

[6] http://www.wg.aegee.org/ewg/bologna.htm

[7] https://ec.europa.eu/education/policy/highereducation/bologna-process_en

[8] https://ec.europa.eu/education/resources/european -credit-transfer-accumulation-system_en

[9] https://www.bau.edu.jo/bauar/deanship/Student_A ffairs/media/19.pdf

[10] https://www.bau.edu.jo/laws/files/laws/instruction 1312.pdf 
[11] http://fsc.scuegypt.edu.eg/attach/2/dalel_altaleb_a lmo5tasar.pdf

[12] http://units.ju.edu.jo/ar/LegalAffairs/Lists/Regulat ions/DispForm.aspx?ID=246\&Cont

entTypeId $=0 \mathrm{x} 0100 \mathrm{C} 7850 \mathrm{~F} 392 \mathrm{E} 786$ A439F935E08870

$8707 \mathrm{E}$ 